\title{
Obstructive Sleep Apnea and COVID-19 Infection Comorbidity: Analysis of the Problem in the Age Aspect
}

\author{
Olga Berdina, PhD; ; Irina Madaeva, $\mathrm{PhD}, \mathrm{ScD}$; \\ Lyubov Rychkova, $\mathrm{PhD}, \mathrm{ScD}$, Corresponding Member of the RAS \\ Scientific Centre for Family Health and Human Reproduction Problems \\ Irkutsk, the Russian Federation
}

\begin{abstract}
In the literature, there are suggestions of a possible mutual influence between obstructive sleep apnea (OSA) and the novel coronavirus disease 2019 (COVID-19). The aim of this review is to analyze data found in the literature related to pathogenetic aspects of the impact of OSA on COVID-19, and vice versa, and features of the course of this comorbidity in both adulthood and childhood. Information was searched in MEDLINE, PubMed, EBSCO, and RSCI databases, which presented some data for the connection between COVID-19 and OSA, as well as aspects of OSA and COVID-19 comorbidity for adults and the elderly. The common pathophysiological pathways leading to increased systemic inflammation and adverse consequences of OSA and COVID-19 infection do coexist and were revealed in detail. We paid special attention to aspects of this comorbidity in children, and found that research in this area was lacking. Based on this information, it should be concluded that: 1) more pediatric studies of links between OSA and COVID-19 are urgently needed; 2) screening hospitalized COVID-19 patients with tools to detect OSA could identify those at risk for a severe course of these diseases and adverse outcomes; 3 ) treating OSA will allow increasing the likelihood of developing a robust and long-lasting post-COVID-19 adaptive immunity in these patients. (International Journal of Biomedicine. 2020;10(4):312-315.)
\end{abstract}

Key Words: obstructive sleep apnea $\bullet$ COVID- $19 \bullet$ comorbidity $\bullet$ pathogenesis $\bullet$ adults $\bullet$ children

$\mathrm{J}^{\mathrm{us}}$ ust over half a year has passed since the World Health Organization (WHO) declared the COVID-19 outbreak a public health emergency of international concern. At the time, there were only 100 cases outside of China and no deaths. Since then, the incidence has been increasing exponentially, affecting every country in the world. WHO data, published on August 16, 2020, reported 21,294,845 cases of COVID-19 worldwide, with 761,779 deaths, but on September 21, 2020, reported 30,949,804 cases in 235 countries, and 959,116 deaths. ${ }^{(1)}$ The number of new cases of COVID-19 increases week by week and reaches 2,000,000 per week (Fig.1). ${ }^{(2)}$ In the Russian Federation as of September 21, 2020, the number of cases of COVID-19 infection was $1,109,595$, with 6,196 deaths. ${ }^{(3)}$ The COVID-19 pandemic has placed an enormous burden on the global health care system

*Corresponding author: Olga Berdina, PhD, MD. Leading researcher, Laboratory of Somnology and Neurophysiology, Scientific Centre for Family Health and Human Reproduction Problems; Irkutsk, Russia.E-mail: goodnight_84@mail.ru with numerous consequences. The secondary effects of this pandemic, along with major disruptions to essential health care services, are having a huge impact on politics, the economy, and people's daily lives.

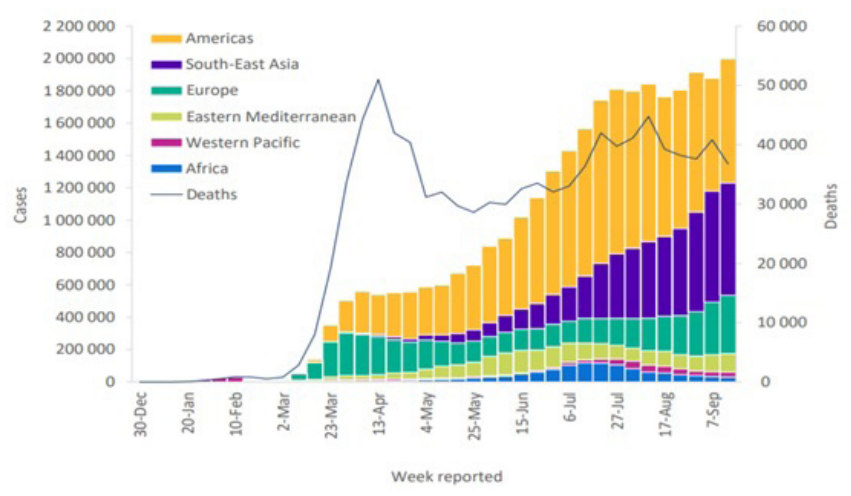

Fig. 1. Number of COVID-19 cases reported weekly by worldwide and global deaths, December 2019 through September 2020 (adapted from (2). 
COVID-19 was predominantly more prevalent among adults and the elderly at the beginning of the outbreak, and the percentage of confirmed cases among children and adolescents was relatively small. The Chinese Novel Coronavirus Pneumonia Emergency Response Epidemiology Team reported that about $2 \%$ of 44,672 confirmed cases of COVID-19 in China through February 11, 2020, were children between 0 and 19 years of age, ${ }^{(4)}$ of these, $0.9 \%$ were subjects younger than 10 years old. One month later in Italy, Livingston et al. found that $1.2 \%$ of all confirmed cases $(22,512)$ of COVID-19 were children, with no deaths. ${ }^{(5)}$ At the same time, of 4,226 COVID-19 cases detected in the United States, $5 \%$ were children ${ }^{(6)}$ Importantly, more than $90 \%$ of ill children were asymptomatic or had mild or moderate symptoms of COVID-19 infection. Since then, the number of child COVID-19 cases has increased significantly, especially in younger age groups, and the disease increasingly began to manifest with so-called "pediatric multisystem inflammatory syndrome $\rangle^{(7)}$ with severe outcomes; ${ }^{(8)}$ therefore, high attention and care should be directed to children and adolescents with COVID-19, just like adult patients. It was shown that COVID-19 is an acute, self-limiting disease, but some patients can die, according to Xu's et al. reported mortality rate of $2 \%$ in adults. ${ }^{(9)}$ The Centers for Disease Control and Prevention (CDC) has published data of deaths involving COVID-19 with a focus on ages 0-18 years in the United States, and on August 26, 2020, reported that in the US there were 29 deaths among children aged 0-4 and 65 among those aged 5-18 years. ${ }^{(10)}$

Some studies have reported a higher COVID-19 incidence in men than in women $(0.31 / 100,000$ vs $0.27 / 100,000$, respectively). ${ }^{(1)}$ Wherein, the case mortality rate for males was also higher than for females ( $2.8 \%$ vs $1.7 \%$, respectively), with a similar trend in children and adolescents, reported by the CDC in the US. ${ }^{(10)}$ It has also been proven that the risk of infection and complications increases significantly in the presence of comorbidities (both adults and children): Patients who reported no comorbid diseases had lower mortality rates than those with comorbid conditions, such as cardiovascular diseases, diabetes, chronic obstructive pulmonary disease, or cancer. ${ }^{(4,12)}$

All of the above-mentioned prompted us to closely study the features of the pathogenetic mechanisms and relationships between COVID-19 and one comorbidity, namely OSA, that is very important for the health care of both adults and children. It should be noted that, despite the obvious relevance and severity of this problem worldwide and numerous discussions in the foreign literature, there are many works of Russian scientists about COVID-19 infection and coexisting diseases in adults, ${ }^{(13,14)}$ while only one publication is devoted to the association between COVID-19 and OSA. ${ }^{(15)}$ But there are no Russian publications, and just a single foreign one, on this problem in pediatric patients.

The aim of this review is to analyze data found in the literature related to pathogenetic aspects of the impact of OSA on COVID-19, and vice versa, and features of the course of this comorbidity in both adulthood and childhood.

Information was searched in MEDLINE, PubMed, EBSCO, and RSCI databases.

OSA and COVID-19 infection in adults and the elderly By definition, OSA is a condition characterized by recurrent episodes of upper airway obstruction during sleep, due to anatomical narrowing of the airway, arousals, and recurrent nocturnal intermittent hypoxemia. ${ }^{(16)}$ OSA is common and the incidence is increasing worldwide. Interestingly, the rate of the condition has a gender dimorphism, as in COVID-19. It is estimated that OSA affects $27 \%$ of men and $11 \%$ of women in the middle-aged adult population. ${ }^{(17)}$ This disease is significantly underdiagnosed, due to lack of awareness and its insidious course, and often remains untreated.

OSA is strongly associated with COVID-19 comorbidities, namely cardiovascular disease, hypertension, diabetes, and obesity. ${ }^{(18)}$ Studies published from April to September 2020, worldwide, on adult and elderly subjects highlighted the strong overlap between OSA and the risk factors for adverse outcomes of COVID-19 infection. ${ }^{(19-27)}$ It is known that, both in patients with OSA and COVID-19 infection, there are associations with increased systemic concentrations of IL-6, IL-17, TNF- $\alpha$ and other pro-inflammatory mediators (e.g., "cytokine storm") $(28,29)$ as well as oxidative stress (inevitably accompanying OSA and coexisting diseases), ${ }^{(30,31)}$ which confirms the possibility of potentiating systemic inflammation in the case of their comorbidity and acts as a major determinant of the adverse consequences of these coexisting diseases (Fig.2). Suen et al. has reported that OSA can potentially aggravate inflammation in COVID-19-related sepsis or acute respiratory distress syndrome. ${ }^{(32)}$ The CORONADO study showed highly significant associations between OSA and the risk of death on day 7 of COVID-19 disease (adjusted OR 2.65). ${ }^{(33)}$ Cade et al. also described OSA as a risk factor for COVID-19 mortality and severe morbidity, highlighting the need for close monitoring of patients with OSA who become infected. ${ }^{(34)}$

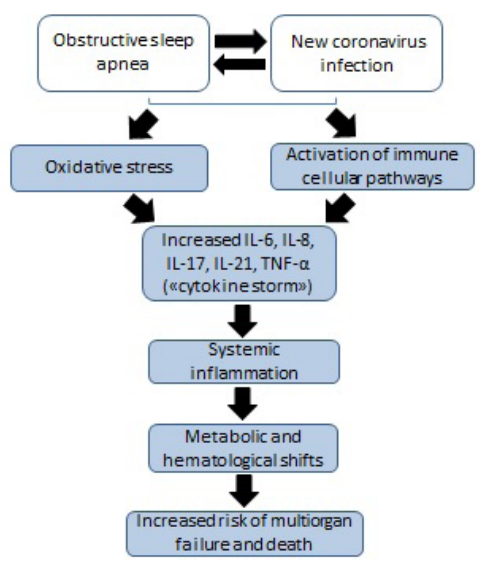

Fig. 2. The common schema illustrating of a cascade of pathophysiological pathways that result in increased systemic inflammation and adverse consequences if obstructive sleep apnea and COVID-19 infection are comorbidity.

There are suggestions of possible links of mutual influence of OSA and COVID-19. OSA could be also added to the severity of the pulmonary inflammatory process of COVID-19 infection. An increased incidence of OSA in COVID-19 patients through the dysregulation of the renin-angiotensin system and hypertension, ${ }^{(35)}$ as well as hyperinflammatory response, ${ }^{(32)}$ which can occur in COVID-19 pneumonia, can 
cause multiorgan failure. ${ }^{(36)}$ Furthermore, management of OSA patients with COVID-19 infection requires special care and precautions. $^{(37,38)}$

Children's aspects of OSA and COVID-19 comorbidity

It is well known that OSA affects $1 \%-5 \%$ of all children and adolescents ${ }^{(39)}$ and is associated with COVID-19 comorbidities (e.g. hypertension and obesity), as in adults and the elderly, ${ }^{(40-42)}$ which along with the appearance of COVID-19-induced lung injury in children and an almost equal OSA and COVID-19 incidence in the pediatric population, is a serious problem for children's healthcare services. Despite increasing evidence showing children have more mild presentations and better outcomes with COVID-19, there is very limited documentation in the medical literature of apnea cases, especially coexisting OSA, potentially aggravating the course of the disease. It has been reported that sleep-disordered breathing in children and adolescents with COVID-19 may manifest by episodes of apnea. In three studies, Needleman et al., ${ }^{(43)}$ Brabin et al.,${ }^{(44)}$ and Enner et al. ${ }^{(45)}$ described COVID-19-associated apnea and circumorally cyanosis in a 3-week-old, full-term male infant; and neonatal apnea as initial manifestation of COVID-19 infection (a type of apnea was not marked: central or obstructive in both cases), and COVID-19-associated encephalopathy characterized by focal seizures and central apnea in a 14-year-old girl. We found information about a 3-year-old boy with Down syndrome and many comorbidities, including OSA, with dependence on continuous positive airway pressure (CPAP), who was infected by COVID-19, prompting development of mild hypotension and the need for an increase in CPAP ${ }^{(46)}$ Today, this is perhaps the only finding about a case of COVID-19 infection in a pediatric patient with OSA as a chronic lung disease.

\section{Conclusion and outlook}

Based on our analysis, it can be concluded that such a serious problem as COVID-19 infection against the background of coexisting diseases, namely chronic respiratory pathology, for example OSA, in adult and elderly patients is being carefully studied and widely discussed by scientists from many countries. However, there are few studies in the pediatric population are single, which urgently necessitates research into links between OSA and COVID-19 in childhood and adolescence. It should also be remembered that screening hospitalized COVID-19 patients with tools to detect OSA (subjective or/and objective, such as polysomnography) could identify those at risk for adverse outcomes, and by subsequently restoring adequate sleep, we can not only reduce the incidence of complications in such patients but also increase the likelihood of developing a robust and long-lasting post-COVID-19 adaptive immunity.

\section{Competing Interests}

The authors declare that they have no competing interests.

\section{References}

1. WHO. Coronavirus Disease (COVID-19). Situation Report - 209. Available at https://www.who.int/docs/defaultsource/coronaviruse/situation-reports/20200816-covid-19sitrep-209.pdf?sfvrsn=5dde1ca2_2. Data as received by WHO from national authorities by 10:00 CEST, 16 August 2020 2. WHO. Coronavirus disease (COVID-19). Available at https://www.who.int/docs/default-source/coronaviruse/ situation-reports/20200921-weekly-epi-update-6. pdf? sfvrsn=d9cf9496 4. Data as received by WHO from national authorities, as of 10 am CEST 20 September 2020

3. WHO/Europe. COVID-19 situation in the WHO European Region. Regional Office for Europe; 2020. Available at https:// who.maps.arcgis.com/apps/opsdashboard/index.html\#/ ead3c6475654481ca51c248d52ab9c61

4. Epidemiology Working Group for NCIP Epidemic Response, Chinese Center for Disease Control and Prevention. [The epidemiological characteristics of an outbreak of 2019 novel coronavirus diseases (COVID-19) in China]. Zhonghua Liu Xing Bing Xue Za Zhi. 2020 Feb 10;41(2):145-151. Chinese. doi: 10.3760/cma.j.issn.0254-6450.2020.02.003. PMID: 32064853. [Article in Chinese]

5. Livingston E, Bucher K. Coronavirus Disease 2019 (COVID-19) in Italy. JAMA. 2020 Apr 14;323(14):1335. doi: 10.1001/jama.2020.4344.

6. CDC COVID-19 Response Team. Severe Outcomes Among Patients with Coronavirus Disease 2019 (COVID-19) - United States, February 12-March 16, 2020. MMWR Morb Mortal Wkly Rep. 2020 Mar 27;69(12):343-346. doi: 10.15585/ mmwr.mm6912e2.

7. WHO. Multisystem inflammatory syndrome in children and adolescents temporally related to COVID-19. Scientific Brief. 15 May 2020. Available at https://www.who.int/ news-room/commentaries/detail/multisystem-inflammatorysyndrome-in-children-and-adolescents-with-covid-19

8. Riphagen S, Gomez X, Gonzalez-Martinez C, Wilkinson $\mathrm{N}$, Theocharis P. Hyperinflammatory shock in children during COVID-19 pandemic. Lancet. 2020 May 23;395(10237):16071608. doi: 10.1016/S0140-6736(20)31094-1.

9. Xu Z, Shi L, Wang Y, Zhang J, Huang L, Zhang C, et al. Pathological findings of COVID-19 associated with acute respiratory distress syndrome. Lancet Respir Med. 2020 Apr;8(4):420-422. doi: 10.1016/S2213-2600(20)30076-X. Epub 2020 Feb 18. Erratum in: Lancet Respir Med. 2020 Feb 25.

10. CDC. Centers for Disease Control and Prevention. Provisional COVID-19 Deaths: Focus on Ages 0-18 Years. Deaths involving coronavirus disease 2019 (COVID-19) with a focus on ages 0-18 years in the United States. Available at https://data.cdc.gov/NCHS/Provisional-COVID-19-DeathsFocus-on-Ages-0-18-Yea/nr4s-juj3

11. Yang Y, Lu Q, Liu M, Wang Y, Zhang A, Jalali N, et al. Epidemiological and clinical features of the 2019 novel coronavirus outbreakinChina. medRxiv2020.02.10.20021675; doi: $10.1101 / 2020.02 .10 .20021675$

12. Lu X, Zhang L, Du H, Zhang J, Li Y, Quet J, et al.; Chinese Pediatric Novel Coronavirus Study Team. SARSCoV-2 Infection in Children. N Engl J Med. 2020 Apr 23;382(17):1663-1665. doi: 10.1056/NEJMc2005073.

13. Shinkin MV, Zvenigorodskaya LA, Mkrtumyan AM. [COVID-19 and diabetes mellitus: what we know about it]. Effective pharmacotherapy. 2020;16(17):26-33. doi: 10.33978/2307-3586-2020-16-17-26-33. [Article in Russian]. 14. Kravchuk EN, Neimark AE, Babenko AYu, Grineva EN. [Obesity and COVID-19]. Arterial Hypertension. 2020;26 (4):439-445. doi: 10.18705 / 1607-419X-2020-26-4-440-446. [Article in Russian].

15. Buzunov RV. [Obesity and sleeping breathing disorders as risk factors of severe COVID-19]. Date accessed: September 
15 2020. Available at https://buzunov.ru/osas_covid/. [Article in Russian].

16. Dehlink E, Tan HL. Update on paediatric obstructive sleep apnoea. J Thorac Dis. 2016 Feb;8(2):224-35. doi: 10.3978/j. issn.2072-1439.2015.12.04.

17. Peppard PE, Young T, Barnet JH, Palta M, Hagen EW, Hla KM. Increased prevalence of sleep-disordered breathing in adults. Am J Epidemiol. 2013;177(9):1006-14. doi: 10.1093/aje/kws342. 18. Jordan AS, McSharry DG, Malhotra A. Adult obstructive sleep apnoea. Lancet. 2014 Feb 22;383(9918):736-47. doi: 10.1016/S0140-6736(13)60734-5.

19. Ciment AJ, Ciment LM. A 55-year-old COVID-19positive man managed with self-regulation of high-flow oxygen by high-velocity nasal insufflation therapy. Respirol Case Rep. 2020 May 21;8(5):e00591. doi: 10.1002/rcr2.591.

20. Memtsoudis SG, Ivascu NS, Pryor KO, Goldstein PA. Obesity as a risk factor for poor outcome in COVID-19-induced lung injury: the potential role of undiagnosed obstructive sleep apnoea. Br J Anaesth. 2020 Aug;125(2):e262-e263. doi: 10.1016/j.bja.2020.04.078.

21. Mittal A, Forte M, Leonard R, Sangani R, Sharma S. Refractory Acute Respiratory Distress Syndrome Secondary to COVID-19 Successfully Extubated to Average Volumeassured Pressure Support Non-invasive Ventilator. Cureus. 2020 Apr 27;12(4):e7849. doi: 10.7759/cureus.7849.

22. Kragholm K, Andersen MP, Gerds TA, Butt JH, Østergaard L, Polcwiartek C, et al. Association between male sex and outcomes of Coronavirus Disease 2019 (Covid-19) - a Danish nationwide, register-based study. Clin Infect Dis. 2020 Jul 8:ciaa924. doi: 10.1093/cid/ciaa924.

23. Huang JF, Wang XB, Zheng KI, Liu WY, Chen JJ, George J, Zheng MH. Letter to the Editor: Obesity hypoventilation syndrome and severe COVID-19. Metabolism. 2020 Jul;108:154249. doi: 10.1016/j.metabol.2020.154249.

24. Tufik S, Gozal D, Ishikura IA, Pires GN, Andersen ML. Does obstructive sleep apnea lead to increased risk of COVID-19 infection and severity? J Clin Sleep Med. 2020 Aug 15;16(8):1425-1426. doi: 10.5664/jcsm.8596.

25. McSharry D, Malhotra A. Potential influences of obstructive sleep apnea and obesity on COVID-19 severity. J Clin Sleep Med. 2020 Sep 15;16(9):1645. doi: 10.5664/jcsm.8538.

26. Woo J, Weber G, Nathan N. A COVID-19 Conundrum: Obstructive Sleep Apnea (OSA) and Noninvasive Ventilation (NIV). Anesth Analg. 2020 Aug;131(2):317. doi: 10.1213/ ANE.0000000000004998.

27. Salles C, Mascarenhas Barbosa H. COVID-19 and obstructive sleep apnea. J Clin Sleep Med. 2020 Sep 15;16(9):1647. doi: 10.5664/jcsm.8606.

28. Kheirandish-Gozal L, Gozal D. Obstructive Sleep Apnea and Inflammation: Proof of Concept Based on Two Illustrative Cytokines. Int J Mol Sci. 2019 Jan 22;20(3):459. doi: 10.3390/ ijms20030459.

29. Martusevich A, Karuzin K, Zhdanova O. Immune and Metabolic Response to COVID-19 Infection: Review for Molecular Pathways. International Journal of Biomedicine. 2020;10(3):177-181. doi: 10.21103/Article10(3)_RA1.

30. Darenskaya MA, Gavrilova OA, Rychkova LV, Kravtsova OV, Grebenkina LA, Osipova EV, et al. The assessment of oxidative stress intensity in adolescents with obesity by the integral index. International Journal of Biomedicine. 2018;8(1):37-41. doi: 10.21103/Article8(1) OA5.

31. Kolesnikova LI, Madaeva IM, Semenova NV, Vlasov BY, Grebenkina LA, Darenskaya MA, Dolgikh MI. Antioxidant potential of the blood in men with obstructive sleep breathing disorders. Bull Exp Biol Med. 2013;154(6):731-3. doi: 10.1007/s10517-013-2041-4.

32. Suen CM, Hui DSC, Memtsoudis SG, Chung F. Obstructive Sleep Apnea, Obesity, and Noninvasive Ventilation: Considerations During the COVID-19 Pandemic. Anesth Analg. 2020 Aug;131(2):318-322. doi: 10.1213/ ANE.0000000000004928.

33. Cariou B, Hadjadj S, Wargny M, Pichelin M, Al-Salameh A, Allix I, et al.; CORONADO investigators. Phenotypic characteristics and prognosis of inpatients with COVID-19 and diabetes: the CORONADO study. Diabetologia. 2020 Aug;63(8):1500-1515. doi: 10.1007/s00125-020-05180-X.

34. Cade BE, Dashti HS, Hassan SM, Redline S, Karlson EW. Sleep Apnea and COVID-19 Mortality and Hospitalization. Am J Respir Crit Care Med. 2020 Sep 18. doi: 10.1164/ rccm.202006-2252LE.

35. Ekiz T, İnönü Köseoğlu H, Pazarlı AC. Obstructive sleep apnea, renin-angiotensin system, and COVID-19: possible interactions. J Clin Sleep Med. 2020 Aug 15;16(8):14031404. doi: $10.5664 /$ jcsm. 8576 .

36. McSharry D, Malhotra A. Potential influences of obstructive sleep apnea and obesity on COVID-19 severity. J Clin Sleep Med. 2020 Sep 15;16(9):1645. doi: 10.5664/jcsm.8538.

37. Attias D, Pepin JL, Pathak A. Impact of COVID-19 lockdown on adherence to continuous positive airway pressure by obstructive sleep apnoea patients. Eur Respir J. $2020 \mathrm{Jul}$ 30;56(1):2001607. doi: 10.1183/13993003.01607-2020.

38. Ferioli M, Cisternino C, Leo V, Pisani L, Palange P, Nava S. Protecting healthcare workers from SARS-CoV-2 infection: practical indications. Eur Respir Rev. $2020 \mathrm{Apr}$ 3;29(155):200068. doi: 10.1183/16000617.0068-2020.

39. Marcus CL, Brooks LJ, Draper KA, Gozal D, Halbower AC, Jones J, et al.; American Academy of Pediatrics. Diagnosis and management of childhood obstructive sleep apnea syndrome. Pediatrics. 2012;130(3):e714-55. doi: 10.1542/peds.2012-1672.

40. Ehsan Z, Ishman SL. Pediatric Obstructive Sleep Apnea. Otolaryngol Clin North Am. 2016 Dec;49(6):1449-1464. doi: 10.1016/j.otc.2016.07.001.

41. Berdina O, Madaeva I, Rychkova L, Bugun O, Kolesnikova L. Obstructive sleep apnea as predictor of cardiovascular risk factors in male adolescents with essential hypertension. Sleep Med 2017;40(Suppl. 1):e31.7.

42. Madaeva I, Berdina O, Mandzyak T, Kolesnikov S, Kolesnikova L. Sleep patterns in adolescents with hypertension. International Journal of Biomedicine. 2016;6(1):53-55. doi: 10.21103/Article6(1)_OA11.

43. Needleman JS, Hanson AE. COVID-19-associated apnea and circumoral cyanosis in a 3-week-old. BMC Pediatr. 2020 Aug 12;20(1):382. doi: 10.1186/s12887-020-02282-8.

44. González Brabin A, Iglesias-Bouzas MI, Nieto-Moro M, Martínez de Azagra-Garde A, García-Salido A. [Neonatal apnea as initial manifestation of SARS-CoV-2 infection]. An Pediatr (Barc). 2020;93(3):215-216. Spanish. doi: 10.1016/j.anpedi.2020.05.008. 45. Enner S, Hormozdyaran S, Varughese R, Milillo J, Pavkovic I, Laureta E, et al. Central Apnea in an Adolescent With COVID-19. Pediatr Neurol. 2020 Sep;110:87-88. doi: 10.1016/j.pediatrneurol.2020.05.012.

46. Krishnan US, Krishnan SS, Jain S, Chavolla-Calderon MB, Lewis M, Chung WK, Rosenzweig EB. SARS-CoV-2 Infection in Patients with Down Syndrome, Congenital Heart Disease, and Pulmonary Hypertension: Is Down Syndrome a Risk Factor? J Pediatr. 2020;225:246-248. doi: 10.1016/j.jpeds.2020.06.076. 